\title{
Comentário à jurisprudência do Tribunal de Justiça da União Europeia em matéria de vestuário religioso e discriminação no local de trabalho
}

\section{DAVIDE ARGIOLAS}

Prof. Auxiliar ISCAL

Investigador Ratio Legis

\section{Introdução}

Numa Europa cada vez mais plural e fragmentada, vacilante entre a aceitação do multiculturalismo e a sua rejeição de sabor iliberal, coloca-se de forma cada vez mais intensa o problema da acomodação na sociedade das práticas dos grupos religiosos minoritários. Dentro desta temática, assume particular relevância a possibilidade de os trabalhadores manifestarem a própria identidade religiosa no local de trabalho, não tanto através de atividades proselitistas - geralmente proibidas ou fortemente limitadas - mas pela simples utilização de símbolos (e.g., uma cruz) ou indumentária de conotação religiosa (e.g., o hijab, o quipá ou o turbante) que revelem externamente a sua profissão de fé. Apesar de se tratar de um tema que afeta transversalmente todas as religiões, inclusive as de matriz cristã, acaba por ser particularmente relevante para algumas confissões minoritárias, tais como os muçulmanos, os siques ou os judeus, que habitualmente utilizam símbolos visíveis e facilmente reconhecíveis que revelam externamente a sua identidade religiosa.

Trata-se de uma questão sobre a qual já se pronunciaram numerosas jurisdições nacionais, com êxitos bastante diferentes. De facto, há ordenamentos jurídicos, como a França e a Bélgica, mais restritivos no que diz respeito à expressão da própria identidade religiosa 
no âmbito laboral, e outros, como a Inglaterra, mais liberais ${ }^{1}$. Além disso, o próprio Tribunal Europeu dos Direitos do Homem (a seguir, TEDH) emitiu importantes acórdãos sobre o assunto $^{2}$. Mais recentemente, também o Tribunal de Justiça da União Europeia (a seguir, TJUE) e, mais precisamente, o Tribunal de Justiça (a seguir, TJ), se debruçou sobre o tema em dois acórdãos resultantes de pedidos de decisões prejudiciais vindos de França e da Bélgica. Os acórdãos, proferidos no mesmo dia, são: Samira Achbita e Centrum voor gelijkheid van kansen en voor racismebestrijding c. G4S Secure Solutions NV, C-157/15, ECLI:EU:C:2017:203 (a seguir, Achbita), e Asma Bougnaoui e Association de défense des droits de l'homme (ADDH) c. MIcropole, SA, C-188/15, ECLI:EU:C:2017:204 (a seguir, Bougnaoui). Os dois acórdãos, que recorrem amplamente à jurisprudência do TEDH sobre esta matéria, receberam muito atenção mediática, assim como algumas críticas tanto do meio académico quanto de organizações de defesa dos direitos humanos, que acusaram o TJ de perfilhar uma atitude contraditória e de ter perdido uma oportunidade fulcral para fomentar a diversidade e a integração religiosa no solo europeu. Uma vez que se trata de decisões umbilicalmente ligadas, analisá-las-emos conjuntamente.

\section{O plano normativo}

Tanto o caso Achbita quanto o Bougnaoui vertem sobre a interpretação de normas da Diretiva 2000/78/CE do Conselho, de 27 de novembro de 2000, que estabelece um quadro geral para assegurar a igualdade de tratamento entre as pessoas da UE no local de trabalho, independentemente da religião ou das convicções, de uma deficiência, da idade ou da orientação sexual. Apesar de a economia deste artigo não permitir uma análise exaustiva, é mister despender algumas palavras acerca deste ato normativo, explicando os aspetos que mais de perto influenciaram as decisões do TJ.

A Diretiva 2000/78/CE integra o amplo leque de atos normativos europeus que desenvolvem o direito das pessoas à igualdade perante a lei e à proteção contra discriminações, reconhecido em vários diplomas internacionais, assim como no próprio Direito Originário da UE. Deste leque constam, entre outros, a Diretiva 76/207/CEE do Conselho, de 9 de fevereiro de 1976, relativa à igualdade de tratamento entre homens e mulheres, assim como a mais recente Diretiva 2000/43/CE, relativa às discriminações em razão da origem racial e étnica.

1 VICKERS, Lucy - Achbita and Bougnaoui: One Step Forward and Two Steps Back for Religious Diversity in the Workplace. In European Labour Law Journal. Mortsel. ISSN 2399-5556. V. 8, N. ${ }^{\circ}$ 3, 2017, p. 232-257.

2 Cf., em particular, Eweida e Outros c. Reino Unido, queixa n. ${ }^{\circ} 48420 / 2010,59842 / 2010,51671 / 2010$ e 36516/2010, de 15 de janeiro 2013; Ebrahimian c. França, queixa n. ${ }^{\circ}$ 64846/2011, de 26 novembro 2015. 
Central para a compreensão da Diretiva é a distinção entre discriminação direta e indireta. Nos termos do art. ${ }^{\circ}$ 2. $^{\circ}$, existe discriminação direta sempre que alguém seja objeto de um tratamento menos favorável do que aquele que é, tenha sido ou possa a vir ser dado a outra pessoa em situação comparável (art. ${ }^{\circ} 2^{\circ}{ }^{\circ}$, n. ${ }^{\circ}$ 2, al. a)); existe discriminação indireta, ao invés, quando pessoas com uma determinada religião, convicção, deficiência, orientação sexual ou idade se encontrem potencialmente desfavorecidas, em comparação com as demais, devido a uma disposição, critério ou prática aparentemente neutras (art. ${ }^{\circ}{ }^{\circ} .^{\circ}, \mathrm{n} \cdot .^{\circ} 2$, al. b)).

No entanto, a Diretiva admite derrogações à proibição de discriminações. Em primeiro lugar, o art. $^{\circ} 2 .^{\circ}$, n. ${ }^{\circ}$ 2, al. b) especifica que não há discriminação indireta se a disposição, critério ou prática aparentemente neutras sejam objetivamente justificadas por um objetivo legítimo, e desde que os meios utilizados para alcançar este mesmo objetivo sejam proporcionais, ou, para utilizar a linguagem da Diretiva, adequados e necessários.

Além disso, são admitidas outras derrogações, que se aplicam tanto à discriminação direta quanto à indireta. Deixando para outro ensejo as derrogações não referidas nas decisões em apreço, destacamos apenas a do art. $^{\circ} 4 .^{\circ}$, n. ${ }^{\circ} 1$, que permite aos Estados-Membros preverem na sua legislação nacional que uma diferença de tratamento baseada numa característica relacionada com a religião ou as convicções, uma deficiência, a idade ou a orientação sexual não constitua discriminação se, em virtude da atividade profissional em causa ou do contexto da sua execução, esta mesma característica constitua um requisito essencial e determinante para o exercício dessa atividade, e desde que o objetivo seja legítimo e o requisito proporcional.

\section{Os factos dos litígios nos processos principais e as questões prejudiciais}

$\mathrm{O}$ caso Achbita diz respeito à $\mathrm{G}_{4} \mathrm{~S}$ Secure Solutions, uma empresa que presta serviços de segurança e vigilância. A G4S persegue uma política de neutralidade religiosa, política e filosófica, razão pela qual proíbe aos seus trabalhadores, como consta no seu regulamento, de "exibir no lugar de trabalho sinais visíveis das suas convicções políticas, filosóficas ou religiosas e/ou praticar qualquer ritual decorrente de tais convicções". A trabalhar na empresa desde 2003, S. Achbita sempre cumprira com esta obrigação, apesar de ser de confissão muçulmana e de utilizar o véu islâmico fora do serviço. No entanto, em $2006 \mathrm{~S}$. Achbita informou os responsáveis da empresa que, a partir daquele momento, pretendia utilizar o véu islâmico também durante o horário de trabalho. Apesar de ter sido informada pela direção da empresa que a sua decisão seria contrária à política empresarial, Achbita 
não desistiu da sua resolução, chegando por este mesmo motivo a ser despedida em junho de 2006, com direito a indemnização por despedimento.

Inconformada com a situação, S. Achbita intentou uma ação de indemnização por despedimento ilícito e violação da lei antidiscriminação no Tribunal do Trabalho de Antuérpia, tribunal esse que declarou a ação improcedente por inexistência de discriminação direta ou indireta (sentença de 27 de abril de 2010). Em sede de recurso, o Tribunal do Trabalho de Segunda Instância de Antuérpia rejeitou os pedidos da autora, argumentando que o despedimento de S. Achbita não podia ser considerado manifestamente desproporcionado ou discriminatório, uma vez que a empresa não podia ter noção da ilicitude da proibição imposta, dada a divergência de opiniões existentes sobre o assunto (sentença de 23 de dezembro de 2011). Finalmente, S. Achbita interpôs recurso de cassação junto do Tribunal de Cassação da Bélgica. No dia 9 de março de 2015, este órgão jurisdicional decidiu suspender a instância e submeter ao TJ uma questão para decisão a título prejudicial concernente a interpretação do art. $^{\circ} 2 .^{\circ}$, n. $^{\circ}$ 2, al. a) da Diretiva 2000/78/CE, relativa ao conceito de discriminação direta. Mais especificamente, o tribunal de reenvio perguntou se, à luz desta norma, existindo na empresa uma proibição geral de exibir sinais que revelassem as convicções filosóficas, religiosa ou ideológicas, a proibição de uma trabalhadora muçulmana utilizar um lenço de cabeça no local de trabalho pudesse ser considerada uma discriminação direta. Como realçado pela Advogada-Geral Julianne Kokott nas Conclusões Fundamentadas, o Tribunal de Cassação belga pareceu partir do princípio de que, num caso como este, uma discriminação indireta seria aceitável, não se podendo afirmar o mesmo acerca de uma eventual discriminação direta ${ }^{3}$.

A matéria de facto do caso Bougnaoui apresenta similitudes com o caso Achbita, bem como diferenças importantes. A. Bougnaoui, também de confissão muçulmana, fora contratada em 2008 como engenheira de projetos pela Micropole SA, uma empresa francesa de aconselhamento, engenharia e formação especializada. Aquando da entrevista que levara à sua contratação, fora-lhe explicado que, por razões de discrição quanto à expressão das opções pessoais dos trabalhadores, nem sempre A. Bougnaoui poderia utilizar o véu quando estivesse a lidar diretamente com os clientes da empresa, apesar de não existir uma proibição geral neste sentido formalizada na empresa. A seguir a uma deslocação ao estabelecimento da Groupama, cliente da Mircropole SA, responsáveis daquela empresa informaram a Micropole SA que a utilização do véu por parte da engenheira A. Bougnaoui tinha

3 Para uma reconstrução mais aprofundada da matéria de facto, cf. UNIÃO EUROPEIA - CURIA - Tribunal de Justiça da União Europeia. Conclusões da Advogada-Geral Juliane Kokott, Processo C-157/15. [Consultado em: 14/06/2018]. Disponível em: http://curia.europa.eu/juris/document/document.jsf?docid=179082\&doclang=PT. (último acesso: 14 junho 2018). 
desagradado a vários colaboradores. Acrescentaram expressamente o seu desejo de que "não houvesse véu da próxima vez". Diante da recusa da trabalhadora em deixar de utilizar o véu, a empresa despediu-a por carta em junho de 2009. A. Bougnaoui impugnou a decisão de despedimento no Tribunal do Trabalho de Paris em setembro do mesmo ano, alegando tratar-se de um despedimento discriminatório. No entanto, o referido tribunal decidiu que a restrição imposta pela Micropole SA à liberdade religiosa era justificada e proporcional. Em sede de recurso, o Tribunal de Recurso de Paris confirmou a decisão da primeira instância. Chamada a pronunciar-se sobre o assunto, a Secção do Trabalho do Tribunal de Cassação francês decidiu suspender a instância e colocar ao TJ uma questão prejudicial relativa ao art. $^{\circ} 4 .^{\circ}, \mathrm{n}^{\circ}{ }^{\circ} 1$ da Diretiva 2000/78/CE. Mais especificamente, o tribunal supremo francês queria saber se o desejo de um cliente de uma empresa de que os serviços prestados deixem de ser assegurados por uma trabalhadora que utilize o véu islâmico pode ser considerado um requisito profissional essencial e determinante, em razão da natureza da atividade profissional em causa ou das condições da sua execução - podendo assim constituir uma derrogação à proibição de discriminação em razão da religião ou das convicções ${ }^{4}$.

\section{A fundamentação dos acórdãos}

Preliminarmente, é de realçar que, como salientado por Lucy Vickers, o TJ divergiu metodologicamente do TEDH na resolução destas questões. De facto, optou por adotar uma perspetiva teórica focada no conceito de igualdade, rejeitando o human rights approach perfilhado pelo TEDH - opção essa que parte da doutrina considera fomentadora de incongruências entre a jurisprudências dos dois tribunais 5 . Mas vejamos com mais detalhe o teor dos dois acórdãos.

Como se pode ver, as duas questões prejudiciais eram bastante diferentes, incidindo a primeira sobre a distinção entre os conceitos de discriminação direta e indireta, e a segunda sobre a interpretação de uma derrogação válida para ambos os tipos de discriminações. Todavia, sobretudo no caso Achbita o TJ não se cingiu ao teor da questão prejudicial e, com o intuito de fornecer "todos os elementos de interpretação (...) úteis para a decisão do pro-

\footnotetext{
4 Para a reconstrução mais detalhada da matéria de facto, cf. UNIÃO EUROPEIA - CURIA - Tribunal de Justiça da União Europeia. Conclusões da Advogada-Geral Eleanor Sharpston, Processo C-188/15. [Consultado em: 16/06/2018]. Disponivel em: https://eur-lex.europa.eu/legal-content/PT/TXT/HTML/?uri=CELEX:62015CCo188\&from=PT. (último acesso: 16 junho 2018), 22 e ss.; Asma Bougnaoui e Association de défense des droits de l'homme (ADDH) contra Micropole SA, C-188/15.

5 Cf. VICKERS, Lucy, Achbita and..., cit., p. 233.
} 
cesso que lhe foi submetido"6, expandiu o seu raciocínio. Disso resultaram dois acórdãos com conteúdo e fundamentações muito semelhantes.

Antes de tudo, ambos os acórdãos exploram o conceito de "religião". Embora reconheça que a Diretiva não define este conceito, o TJ fá-lo coincidir com a noção de religião contida no art. $^{\circ} 9 .^{\circ}$ da Convenção para a Proteção dos Direitos do Homem e das Liberdades Fundamentais (a seguir, CEDH). Para chegar a esta conclusão, o tribunal refere, como afirmado pelo art. $^{\circ}$ 6. ${ }^{\circ}$ do Tratado da União Europeia (a seguir, TUE) e relembrado pelo considerando 1 da Diretiva 2000/78/CE, que a UE reconhece os direitos fundamentais tais como os garante a CEDH e as tradições constitucionais comuns dos Estados-Membros, e que o art. ${ }^{\circ} 10 .^{\circ}$ da Carta dos Direitos Fundamentais da União Europeia (a seguir, CDFUE) corresponde ao art. $^{\circ}$ 9. ${ }^{\circ}$ da $\mathrm{CEDH}$, em virtude da norma interpretativa contida no art. ${ }^{\circ} 52 .{ }^{\circ}, \mathrm{n} .^{\circ} 3$ da própria CDFUE. Ora, com base no art. $^{\circ} 9 .^{\circ}$ da CEDH, o TJ acolhe um conceito amplo de religião, que abarca tanto o foro interno (crer, mudar de religião, etc.), quanto o foro externo, isto é, a manifestação das próprias convicções religiosas, individual ou coletivamente, em público ou em privado, através do ensino, do culto, de práticas e dos rituais ${ }^{8}$. Este elemento não deixa de ser relevante, uma vez que, à partida, confere proteção jurídica à utilização de vestuário religioso, enquanto manifestação individual em público ou em privado da identidade religiosa.

Centrando-nos agora no caso Achbita, reparamos que, a seguir, o TJ se concentra na questão de saber se a regra interna da $\mathrm{G}_{4} \mathrm{~S}$ efetua uma diferença de tratamento entre os trabalhadores da empresa em razão da sua religião, e se essa diferença constitui uma discriminação direta. De forma bastante concisa, o tribunal conclui não estarmos perante um caso de discriminação direta, uma vez que a proibição em causa se aplica de forma idêntica a todos os funcionários, abarcando quaisquer manifestações de convicções religiosas, filosóficas ou ideológicas, com o intuito de prosseguir uma política de neutralidade empresarial. Em suma, o TJ esclarece que regras empresariais deste tipo não podem ser consideradas discriminações diretas.

6 Achbita, n. ${ }^{\circ} 33$.

7 Esta semelhança entre as fundamentações dos acórdãos é realçada por MESTRE, Bruno - A Jurisprudência recente do TJUE e do TEDH sobre a exibição de símbolos religiosos no local de trabalho: uma leitura à luz do pensamento de Jürgen Habermas. Julgar Online. [Consultado em: 16/06/2018]. Disponível em: http://julgar.pt/a-jurisprudencia-recente-dotjue-e-do-tedh-sobre-a-exibicao-de-simbolos-religiosos-no-local-de-trabalho-uma-leitura-a-luz-do-pensamentode-jurgen-habermas/.. No entanto, parte da doutrina tem acusado o TJUE de assumir posições contraditórias. Neste sentido, cf, por exemplo, VICKERS, Lucy - Headscarves and the Court of Justice of the EU: Discrimination and Genuine Occupational Requirements. In International Labor Rights Case Law. Leiden. ISSN 2405-6901. V. 3, N. ${ }^{\circ} 2,2017$, p. 413-418.

8 Cf. MESTRE, Bruno, A Jurisprudência Recente, cit., p. 6. 
Todavia, a seguir o tribunal decide alargar a sua análise para além do teor da questão prejudicial, com o intuito de auxiliar o juiz nacional a tomar a sua decisão. Partindo do pressuposto de que o juiz nacional poderia concluir pela existência de uma discriminação indireta (isto é, uma norma aparentemente neutra, mas capaz de desfavorecer os seguidores de uma determinada religião), o TJ foca-se na derrogação do $\operatorname{art}^{\circ}{ }^{\circ} 2 .^{\circ}$, n. $^{\circ} 2$, al. b), i), já referida acima. Nesta análise, conclui que:

- a vontade do empregador de manter uma política de neutralidade política, religiosa e filosófica nas relações com os clientes públicos e privados deve ser considerada um objetivo legítimo, alicerçado na liberdade de empresa (art. ${ }^{\circ} 16 .^{\circ}$ da CDFUE) e capaz inclusive de restringir, dentro de certos limites, a liberdade religiosa dos trabalhadores, como consta da jurisprudência do TEDH;

- uma proibição como a que está em apreço é adequada, isto é, apta a garantir o objetivo de criação de uma política de neutralidade empresarial, desde que claramente a sua aplicação seja coerente e sistemática;

- quanto ao caráter necessário, o TJ assume uma atitude compromissória, ao realçar que o tribunal de reenvio deve averiguar se a proibição se aplica apenas aos trabalhadores que contatem com clientes da empresa. Acrescenta que o tribunal de reenvio deverá igualmente verificar se era possível para a $\mathrm{G}_{4} \mathrm{~S}$ oferecer a $\mathrm{S}$. Achbita um posto de trabalho sem contato com os clientes, atendendo aos condicionalismos da empresa e desde que isso não causasse custos adicionais.

Concluindo e sintetizando a sua posição, o TJ afirma que proibições como a implementada pela $\mathrm{G}_{4} \mathrm{~S}$ não constituem discriminações diretas. Podem, porém, ser consideradas discriminações indiretas se, apesar da sua aparente neutralidade, implicarem, de facto, uma desvantagem para os seguidores de uma determinada religião. No entanto, o seu caráter discriminatório fica afastado se forem objetivamente justificadas por um objetivo legítimo (como a implementação de uma política de neutralidade empresarial), e se os meios utilizados para o alcançar forem adequados e necessários.

Passando ao caso Bougnaoui, depois de analisado o conceito de religião, o TJ informa que a decisão de reenvio não permite saber se existe uma regra empresarial interna de caráter aparentemente neutro, mas capaz de desfavorecer os seguidores de uma determinada religião. Admitindo a hipótese de esta regra existir, o tribunal conclui da mesma forma que no caso Achbita.

A seguir, encara a hipótese de o despedimento de A. Bougnaoui não ser a consequência da aplicação de uma regra de neutralidade empresarial, mas antes da vontade do empregador de satisfazer um desejo de um cliente (ser atendido por trabalhadores sem véu islâmico). Em particular, o TJ coloca a questão de saber se a decisão do empregador de satisfazer 
este desejo do cliente deve ser considerada uma discriminação ou se, pelo contrário, pode ser aceite por se encaixar na derrogação prevista no art. $^{\circ} 4 \cdot^{\circ}, \mathrm{n} .{ }^{\circ} 1$ da Diretiva $2000 / 78$. Ora, a este respeito o TJ assume uma postura restritiva, evidenciando que o conceito de "requisito essencial e determinante" para o exercício de uma atividade profissional deve ser interpretado de forma objetiva, tendo em conta a atividade a desempenhar e as exigências que dela emergem. Logo, não pode confundir-se com considerações subjetivas, como a vontade de ir ao encontro aos meros desejos dos clientes.

\section{Apreciação crítica}

Parte da doutrina tem julgado negativamente os dois acórdãos, acusando-os inclusive de serem contraditórios. Não concordamos com esta crítica, uma vez que, em nosso entender, as duas pronúncias seguem a mesma linha de raciocínio, complementando-se mutuamente.

Parece-nos, em particular, que o TJ agiu corretamente ao interpretar de forma restritiva o conceito de "requisito profissional essencial e determinante" na aceção do art. ${ }^{\circ} 4 .^{\circ}, \mathrm{n}^{\circ}{ }^{\circ} 1$. Uma interpretação mais ampla teria certamente resultado numa restrição potencialmente arbitrária da liberdade religiosa dos trabalhadores. No entanto, no que diz respeito ao conceito de discriminação indireta, parece-nos controversa a decisão de considerar a prossecução da neutralidade religiosa, filosófica e ideológica um objetivo legítimo nos termos do art. $^{\circ}{ }^{\circ} .^{\circ}$, n. ${ }^{\circ}$ 2, al. b), i). Senão, vejamos.

A prossecução da neutralidade religiosa no contexto empresarial acaba necessariamente por afetar negativamente determinadas minorias religiosas e, no contexto muçulmano, mais as mulheres do que os homens. Embora as conclusões fundamentadas ao caso Achbita da Advogada-Geral Juliane Kokott pareçam sugerir uma visão simplista da religião, em cujos termos o vestuário religioso assumiria uma importância reduzida para os fiéis ${ }^{9}$, na realidade para muitas pessoas que professam sinceramente uma religião esta questão assume uma importância enorme. Trata-se, até, de uma obrigação não negociável. Daí a pergunta: será legítimo sujeitar estes trabalhadores a um problema de consciência ou a uma custosa escolha entre o emprego e a sua fé?

Claramente, em algumas atividades profissionais a prossecução de uma política de neutralidade pode ser um interesse prevalecente. Assim poderá ser, por exemplo, no caso de órgãos de comunicação social que queiram passar uma imagem de equidistância de todas as opções religiosas e políticas. O mesmo poderá acontecer, eventualmente, no caso de entidades a atuarem em contextos sociais caracterizados por conflitos religiosos, uma vez que

9 Cf. Conclusões da Advogada Geral Juliane Kokott..., cit., pontos 116 a 124. 
estas empresas poderão querer manter-se super partes, evitando qualquer tipo de facciosismo. No entanto, na maior parte dos contextos empresariais a imposição de uma política de neutralidade empresarial não nos parece legítima, tendo em conta os custos colaterais que poderá provocar a nível humano e social. Não esqueçamos que uma tal política de neutralidade representa, ao fim e ao cabo, uma "amputação da identidade", ou, pelo menos, da sua manifestação - algo medularmente ligado ao conceito de dignidade humana.

Ou seja, acreditamos que, ao invés de concluir quase automaticamente pela legitimidade do objetivo de preservar a neutralidade empresarial em nome da liberdade de empresa, este objetivo deveria ser sujeito a um juízo ponderativo com a liberdade religiosa e o próprio princípio da igualdade. E, em nosso entender, os argumentos a favor da liberdade e da igualdade se mostram bem mais convincentes ${ }^{10}$.

No entanto, percebemos - e neste ponto concordamos com a Advogada-Geral Juliane Kokott $^{11}$ - que o princípio de laicidade é declinado de formas diferentes no continente europeu, havendo Estados-Membros, como a França, que o interpretam como uma redução do fenómeno religioso no espaço público e até nalguns contextos privados. Neste sentido, acreditamos que o TJ se tenha sentido obrigado a conferir proteção a uma laicidade assim entendida, uma vez que o TUE obriga a UE a respeitar a identidade nacional dos Estados-Membros assim como vem refletida nas estruturas políticas e constitucionais fundamentais de cada um deles (art. ${ }^{\circ} 4 \cdot^{\circ}, \mathrm{n} \cdot .^{\circ}$ ).

\section{Conclusão}

Embora o nosso juízo em relação à postura jurisprudencial do TJ nesta matéria não seja tão crítico como o de outros autores, acreditamos que os dois acórdãos se mostraram demasiado prudentes e ancorados a um conceito de laicidade desajustado à realidade europeia atual. Numa época de saudosismos nacionalistas e vontade mal disfarçada de copiar modelos iliberais extraeuropeus, a política de neutralidade empresarial poderia ser desvirtuada para um afastamento de determinadas minorias dos contextos empresariais. Numa Europa que está timidamente a aprender a ser plural, seria desejável permitir a livre expressão das identidades religiosas nos vários contextos, reforçando o caráter apenas excecional das proibições. Tanto a liberdade religiosa quanto o princípio de igualdade de tratamento sairiam certamente beneficiados.

10 A importância de um juízo ponderativo deste tipo é sublinhado, numa bela peroração da liberdade de utilizar vestuário religioso, in HHW-JeSuisAchbita!. InInternational Journal of Constitutional Law. Oxford.ISSN 1474-2659.V.15, N. ${ }^{\circ}$ 4, 2017, p. 879-906., disponível em: https://doi.org/10.1093/icon/moyoo1 (último acesso: 21 de junho 2018), p. 882. 11 Cf. Conclusões da Advogada Geral Juliane Kokott..., cit., ponto 125. 